\title{
Exploring Opportunities for Enhancing Innovation in Agriculture: The Case of Oil Palm Production in Ghana
}

\author{
S. Adjei-Nsiah ${ }^{1}$, O. Sakyi-Dawson ${ }^{2} \&$ T. W. Kuyper ${ }^{3}$ \\ ${ }^{1}$ Forest and Horticultural Crops Research Centre, Kade, Institute of Agricultural Research, College of \\ Agriculture and Consumer Sciences, University of Ghana, Legon, Ghana \\ ${ }^{2}$ Agricultural Extension Department, School of Agriculture, College of Agriculture and Consumer Sciences \\ University of Ghana, Legon, Ghana \\ ${ }^{3}$ Department of Soil Quality, Wageningen University and Research Centre, Wageningen, The Netherlands \\ Correspondence: S. Adjei-Nsiah, Forest and Horticultural Crops Research Centre, Kade, Institute of Agricultural \\ Research, College of Agriculture and Consumer Sciences, University of Ghana, Legon, P. O. Box 68, Legon, \\ Ghana. Tel: 233-245-395-251. E-mail: y_nsiah@yahoo.co.uk
}

\author{
Received: April 23, 2012 Accepted: May 22, 2012 Online Published: August 31, 2012 \\ doi:10.5539/jas.v4n10p212 URL: http://dx.doi.org/10.5539/jas.v4n10p212
}

\begin{abstract}
We carried out a study using key informant interviews, focus group discussions and individual interviews to explore opportunities to enhance innovation in the oil palm sector in Ghana. Current technical innovations at the farm level are insufficient to promote sustainable oil palm production and to alleviate poverty because of overriding institutional constraints at the larger-than-farm level. Oil palm was selected for the study for three main reasons: (1) It is considered a national priority crop because of its potential for reducing poverty, (2) It has a wide geographical coverage and (3) It is considered as both food and cash crop. Oil palm has evolved in the past 40 years from a public-sector to a private-sector crop. The study identified the following main actors in oil palm production: small private farms that produce about $80 \%$ of the crop; large-scale industrial estates with their network of smallholder and out-grower farmers who produce to supply their large-scale mechanized processing mills; small-scale semi-mechanized processing mills, medium-scale mechanized mills and secondary processors. Opportunities that will make it rational for farmers to invest in increased production and improved sustainability include: (1) creating institutional conditions that will enable small-scale processors to be integrated into the value chain; (2) organising farmers to be able to negotiate for better deals for themselves; (3) improve system of distribution of improved planting material in regions where accessibility to seedlings of the high-yielding tenera hybrid variety is difficult; and (4) developing new tenancy rules and arrangements that improve the income of tenant farmers and encourage them to invest in increased productivity.
\end{abstract}

Keywords: access to market, crude palm oil, farmers' organizations, palm oil quality, processors, smallholder

\section{Introduction}

Agricultural development depends on how successfully knowledge is generated and used. Over the past two decades, investments in knowledge, especially in the form of science and technology, have featured prominently in attempts at promoting sustainable agricultural development. Although many investments have been quite successful (IAASTD, 2008) it is increasingly recognized that the value of traditional agricultural science is not sufficient to support agricultural innovation (World Bank, 2006; World Bank, 2008). Therefore, agricultural research for development requires a new pathway if it is to remain relevant in the rapidly changing global context (IAASTD, 2008).

An earlier research programme ("Convergence of Sciences"; Van Huis et al., 2007) showed that increasing yields through technical innovations at the farm level alone is not enough to ensure positive impact on poverty reduction since smallholder farmers in West Africa have very small windows of opportunity to improve their livelihoods (Nederlof et al., 2007). There is little for them to gain in increasing productivity under current institutional conditions. Hounkonnou et al. (2012) argued that institutional innovations are essential and that such required innovations must include facilitating adequate remuneration, a minimum level of price stability for 
the small-scale farm sector to encourage investment in increased and more sustainable production, security of tenure, effective political support to combat cheap imports as well as facilitating collective efforts of farmers' organizations to improve access to markets under more favorable terms.

The aim of the current study was to identify opportunities in the oil palm production system of Ghana that will enhance innovations. Oil palm was selected for the following reasons: (1) It is a national priority crop because of its potential for reducing poverty, (2) It has a wide geographical coverage as it can be cultivated in six out of the ten administrative regions of the country and (3) It is considered as both food and cash crop.

In spite of a large array of opportunities that oil palm seems to offer, West African countries in general and Ghana in particular have not demonstrated a convincing preparedness to take advantage of them. The two overriding questions are: (i) what are the main causes for the inability of Ghana to take advantage of opportunities arising from the rapid global development in the oil palm sector; and (ii) what opportunities exist in this sector to help the country to capture its share in this development?

We carried out a study to identify opportunities for innovation in the oil palm sector that will encourage investment in increased production and improved agricultural and environmental practices. Opportunity is defined here as a potential for a group of people to capture value, either through a change in their practices to exploit existing conditions or a change in institutional conditions that allow them to respond from their existing practices or both (Adjei-Nsiah et al., accepted for publication).

\section{Method}

The study was conducted in two phases, an exploratory and an in-depth study phase. The purpose of the exploratory study was to trace the history of oil palm production and to identify major actors. The purpose of the in-depth study was to analyse the institutional conditions that must be improved to encourage smallholders to innovate.

\subsection{Exploratory Study}

For the exploratory study we used literature review, focus group discussions and key informant interviews to collect historical data and background information on government interventions, major actors, imports and exports, trends and constraints in the industry.

\subsection{In-depth Study}

The in-depth study was carried out in the Kwaebibrim and the Ahanta West Districts of the Eastern and Western Regions of Ghana respectively. Criteria used in selecting these areas include the role of oil palm in the livelihoods of the people, the history of oil palm production in these areas (Ahanta West District is one of the first districts in Ghana where commercial oil palm plantations started as far back as in 1912 by the Lever Brothers), proximity to the Oil Palm Research Institute (OPRI) (an institute which produces the commercial tenera seedlings for planting), soil factors (soils in Ahanta West are heavily leached and less fertile than soils in Kwaebibrim District), and the presence of different actors and production systems.

Ahanta West District lies between latitude $4^{\circ} 45^{\prime}$ and $4^{\circ} 56^{\prime} \mathrm{N}$ and longitude $1^{\circ} 58^{\prime}$ and $2^{\circ} 13^{\prime} \mathrm{W}$. The district which covers a total land area of $597 \mathrm{~km}^{2}$ has a population of about 95, 140 (2000 Census). Located within the High Rain Forest Zone, the district experiences bimodal rainfall of over 1, 700 millimeters per annum. The soils are mainly Oxisols, well drained and range from sand to clay. They have low $\mathrm{pH}$ ranging between 3.75 and 4.5 and are relatively infertile (Asamoah, 1998). About 12, 160 households are involved in oil palm cultivation. The total area of land under oil palm cultivation is around 36, 800 ha. Out of this about 30,150 ha is cultivated by smallholders. Located within the district is the NORPALM plantation, a large industrial oil palm estate that purchases the bulk of the palm fruits produced by the smallholders for processing into crude palm oil and palm kernel oil.

Kwaebibrem District lies between latitude $6^{\circ} 22^{\prime}$ and $5^{\circ} 58^{\prime} \mathrm{N}$ and longitude $1^{\circ} 0$ ' and $0^{\circ} 35^{\prime} \mathrm{W}$. The district covers a total area of $1230 \mathrm{~km}^{2}$ and has a population of 179, 209 (Year 2000 Population Census). The soils are mainly forest ochrosols and mainly silty to silty clay loams. They are mostly fertile with moderately acid to neutral $\mathrm{pH}$. The district is located in the semi-deciduous forest zone of Ghana with bi-modal rainfall pattern with peaks in June and October. Total annual rainfall is $1,500 \mathrm{~mm}$. The number of households cultivating oil palm is estimated at 13, 095 (Mr. Kofi Ametepe, Director, Ministry of Food and Agriculture, Kwaebibrim District, personal communication). About $50 \%$ of them produce palm fruits on contract to the Ghana Oil Palm Development Company (GOPDC), which has the capacity to process 60 tons of fresh fruit bunches per hour, the largest of its 
kind in the West African sub-region. A total area of 50, 700 ha are under cultivation in the district, $72 \%$ of which are owned by smallholders.

Within each district three communities within $30 \mathrm{~km}$ radius of large industrial estates were selected. In Ahanta West District, the communities selected were Nyameyawkrom, Ewusiejoe and Aboadze while in Kwaebibrem District the selected communities were Kusi (which is also close to the Oil Palm Research Institute), Abaam and Otumi which are within the catchment area of GOPDC.

Semi-structured questionnaires were used to collect quantitative data on farm sizes, type and source of planting materials, yield data, price of fresh fruit bunches, farming systems, input use, management practices and land tenure. In addition to the individual interviews, focus group discussions were held with community leaders, opinion leaders and leaders of farmer associations. Information was also collected from key informants such as management staff of the large industrial estates and Ministry of Food and Agricultural Staff.

In each community, the list of oil palm farmers were collected from the Agric Extension Agent in charge of the communities or the community leaders. Between 20 and 35 farmers were randomly selected for the interviewing. For crop management practices (planting density, presence of cover crops, use of fertilizer, use of herbicides and frequency of weeding) we tested whether there were significant differences between the six villages, based on $\chi^{2}$ test $(\mathrm{df}=5)$. For oil palm productivity we tested for significant differences between both districts (ANOVA).

\section{Results}

\subsection{Exploratory Study}

Oil palm (Elaeis guineensis) which is a native of West Africa produces two types of oil (palm oil extracted from its fruits and palm kernel oil extracted from the seeds of the fruits). Both types are of industrial importance. Oil palm has evolved from a crop harvested in the wild for export in the mid $19^{\text {th }}$ century to an industratial plantation crop. Palm oil became an important export crop of Ghana [then: Gold Coast] in the nineteenth century for the European market (Amanor, 1994). The discovery of mineral oil that could replace palm oil and the opening of European oil palm plantations in Indonesia and Malaysia led to the collapse of the oil palm industry in Gold Coast. By the 1860s and 1870s world palm oil price declined and the Gold Coast oil palm industry could not produce competitively. Since independence in 1957 various successive governments have made efforts at promoting oil palm as an industrial crop both for local consumption and for export.

The sector still faces international competition mainly from south East Asian countries such as Indonesia and Malaysia. Ghana's inferior competitive ability is due to high production costs, lack of expertise, and unfavorable institutional and environmental factors (Anon, 1999; Basiron, 2007). Currently the total area suitable for oil palm cultivation is estimated at 3,000,000 ha while only 300,000 ha of land is under oil palm cultivation (PSI, 2004). While the fresh fruit bunches in Southeast Asian countries yield around 20 tons/ha (Jalani et al., 2002) those of Ghana yield around 3-6 tons/ ha by small-scale farmers and 11-14 tons per hectare by industrial estates (Opoku and Asante, 2008).

Five main types of actors are recognized in the sector: (1) Large industrial plantations with large-scale processing mills and a network of smallholder and out-grower farmers; (2) Medium-scale plantations with medium-scale industrial mills with a network of out-growers; (3) Small private farmers cultivating less than 10 hectares (4) small-scale processors using semi-mechanized mills with capacities of about 6-8 tons/day and (5) secondary processors who process crude palm oil into refined olein (Figure 1). The industry is supported with research and provision of planting material by the Oil Palm Research Institute of the Council for Scientific and Industrial Research (CSIR). 
FUNCTIONS

ACTORS

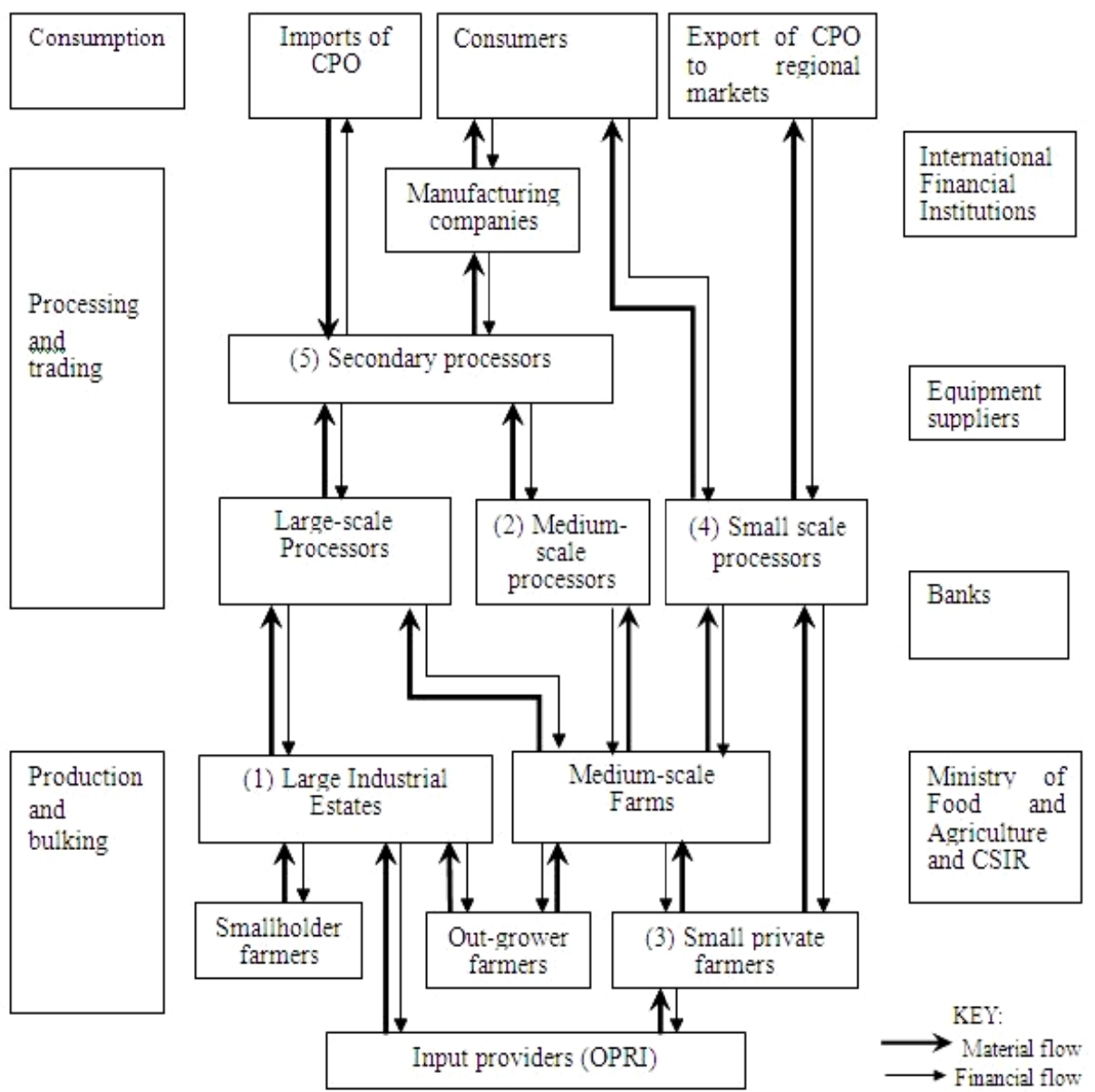

Figure 1. Value chain diagram for the Oil Palm Industry in Ghana (The arrows only indicate flow between the main actors and not flow between actors and supporters)

The role of these various actors in the development of the oil palm sector has evolved over four phases. Between 1957 and 1978, successive governments promoted oil palm production through the establishment of state plantations but these were largely unsuccessful due to poor management, lack of expertise and lack of mills to process the fruits. The next phase of the development of the crop saw the establishment of state-owned large industrial estates in some parts of Eastern, Central and Western Regions with funding from development partners including World Bank, European Union, the Netherlands Government and Unilever between 1975 and 1980. The Structural Adjustment program initiated in the 1980s led to the privatization of most of these companies. Oil palm in recent years has become a small-holders crop, particularly in Eastern, Central and Western Region of Ghana following the devastating effect of bushfires on smallholder cocoa farms in Ghana in 1983. It is estimated that in 2002, around 300, 000 ha was under cultivation with about 250, 000 ha being in the hands of scattered unorganized small-scale (rural) farmers (PSI, 2003). The development of the smallholder oil palm cultivation led to the establishment of medium and small-scale mills in most parts of Eastern, Central and Western Region. The small-scale mills alone have the capacity to produce about $80 \%$ of the total crude palm oil (MASDAR, 2010). The president of the Republic of Ghana in October, 2002 announced a Special Presidential Initiative for the development of the oil palm industry (PSI, 2004). The objective of this initiative was to assist the smallholder farmers to plant improved planting materials (tenera hybrid) and adopt improved agricultural practices that will lead to increased yield.

In recent years, palm oil consumption has increased worldwide particularly in Europe, China and India partly because of the expansion of the bio-fuel industry and the need for cheaper sources of oleo-chemicals (Inyan, 
2002). Also in the West African subregion, there is huge demand for palm oil estimated at 850,000 MT annually (Toledano et al., 2004). Ghana currently seems unable to even fulfill its domestic demand. Ghana currently produces 232,700 MT of crude palm oil (CPO) (MASDAR) annually while its annual total consumption is currently estimated at 252,432 MT (MPOC, 2009). The deficit is met through importation from Southeast Asia (MPOC, 2009, MASDAR, 2010). The major importer of crude palm oil is Unilever which imports about 20, 000 tons of CPO into the country annually. Major consumers of CPO are the soap-manufacturing companies such as Ameen Shangari, PZ and Unilever. It should be noted, however, that a substantial quantity of palm oil, which is produced by small-scale processors, is sold in the Nigerian market and that this quantity is not captured in national production statistics. The implication of growing demand in the oil palm industry is that the sector has opened an array of opportunities for employment generation and poverty reduction, especially among rural dwellers.

\subsection{In-depth Study}

\subsubsection{Innovations}

Technical innovations (i.e., the use of hybrid seedlings, optimal plant spacing, mineral fertilizers and cover crops for soil fertility improvement and herbicides for weed control) are below optimal in the oil palm sector except in some communities within the catchment area of the Ghana Oil Palm Development Company (Table 1) which has introduced these innovations to its farmers as a production package on credit. It is worthy to note that Kusi, one of the communities in the Kwaebibrim District where the use of legume cover crops (mainly Pueraria phaseoloides) is virtually absent, is located outside the catchment area of GOPDC. Farmers in this community usually intercrop oil palm with food crops during the first five years of cropping.

The lack of innovation in the oil palm sector is due to poor interaction among the actors in the sector. Interaction has been missing among major actors (farmers and large industrial estates; farmers and the extension service; and small-scale processors and large industrial estates) partly because of lack of trust.

\subsubsection{Planting Materials}

The use of volunteer seedlings (i.e., progeny of plantation trees, not of hybrid provenance and hence of inferior quality) for planting is very high among farmers in the Ahanta West District in the Western Region compared to that of Kwaebibrim District of the Eastern Region (Figure 2). This practice is common in the Ahanta West District because the source of production of the tenera hybrid seeds (the Oil Palm Research Institute) is far away from the district. Until the introduction of the President Special Initiative on oil palm which also supported the establishment of nurseries for the production of improved planting materials to farmers, OPRI was the only institution that produced certified seeds and seedlings for farmers for planting. Besides its main office at Kusi in the Kwaebibrim District, the institute has no other office in the country from where certified seeds or seedlings could be sourced. Farmers from the Ahanta West District have no option but to pick volunteer seedlings from old plantations established by the state in the early sixties and seventies which farmers erroneously believe could yield as much as the improved planting materials from which they were picked. (The improved oil palm seedlings that are used for establishing commercial oil palm plantations are hybrid materials. Seeds taken from a hybrid may either be sterile or more commonly fail to breed true to type). Figure 2 shows that about $25-75 \%$ of the farmers in the three communities in the Ahanta West District use volunteer seedlings for planting. The variation in the use of tenera planting materials by farmers in the Ahanta West District could be explained by proximity of these communities to NORPALM plantations, one of the nursery operators under the PSI which was tasked to produce planting materials for supply to farmers. Communities that were closer to the nursery and could organize themselves quickly were the ones who had access to tenera materials. Creating institutional conditions for an improved system of distribution of improved planting materials to farmers where accessibility to seedlings of the high-yielding hybrid variety is a bottleneck to production, could thus be one way of improving opportunity in the sector. 
Table 1. Crop management practices among farmers in different communities in Ghana. K: communities in Kwaebibrem District, A: communities in Ahanta West District

\begin{tabular}{|c|c|c|c|c|c|c|c|c|c|}
\hline \multirow[b]{2}{*}{$\begin{array}{l}\text { Management } \\
\text { practice }\end{array}$} & \multicolumn{6}{|c|}{ Community } & \multirow[t]{2}{*}{$\chi^{2}$} & \multirow[t]{2}{*}{ df } & \multirow[t]{2}{*}{ Prob } \\
\hline & $\begin{array}{l}\text { Abaam } \\
(\mathrm{K}) \\
\mathrm{N}=35\end{array}$ & $\begin{array}{l}\text { Otumi } \\
(\mathrm{K}) \\
\mathrm{N}=31\end{array}$ & $\begin{array}{l}\text { Kusi } \\
(\mathrm{K}) \\
\mathrm{N}=26\end{array}$ & $\begin{array}{l}\text { Aboadze } \\
\text { (A) } \\
\mathrm{N}=20\end{array}$ & $\begin{array}{l}\text { Nyameyawkrom } \\
\text { (A) } \\
\mathrm{N}=23\end{array}$ & $\begin{array}{l}\text { Ewusiejoe }(\mathrm{A}) \\
\mathrm{N}=32\end{array}$ & & & \\
\hline $\begin{array}{l}\text { Planting } \\
\text { density (\%) }\end{array}$ & & & & & & & 50.69 & 5 & $<0.001$ \\
\hline 150 plants/ha & 46 & 90 & 27 & 40 & 22 & 9 & & & \\
\hline$>150$ plants/ha & 54 & 10 & 73 & 60 & 78 & 91 & & & \\
\hline Total & 100 & 100 & 100 & 100 & 100 & 100 & & & \\
\hline $\begin{array}{c}\text { Cover crop } \\
(\%)\end{array}$ & & & & & & & 60.54 & 5 & $<0.001$ \\
\hline Present & 69 & 74 & 8 & 15 & 22 & 9 & & & \\
\hline Absent & 31 & 26 & 92 & 85 & 78 & 91 & & & \\
\hline Total & 100 & 100 & 100 & 100 & 100 & 100 & & & \\
\hline Fertilizer use (\% & & & & & & & 23.83 & 5 & $<0.001$ \\
\hline Never & 83 & 52 & 100 & 70 & 83 & 88 & & & \\
\hline Occasional & 17 & 48 & 0 & 30 & 17 & 12 & & & \\
\hline Total & 100 & 100 & 100 & 100 & 100 & 100 & & & \\
\hline Herbicide & & & & & & & 4.98 & 5 & NS \\
\hline Never & 63 & 52 & 50 & 75 & 61 & 69 & & & \\
\hline Occasional & 37 & 48 & 50 & 25 & 39 & 31 & & & \\
\hline Total & 100 & 100 & 100 & 100 & 100 & 00 & & & \\
\hline Frequency of we & eding (\%) & & & & & & 4.30 & 5 & NS \\
\hline Once/year & 6 & 7 & 12 & 15 & 0 & 9 & & & \\
\hline >once/year & 94 & 93 & 88 & 85 & 100 & 91 & & & \\
\hline Total & 100 & 100 & 100 & 100 & 100 & 100 & & & \\
\hline
\end{tabular}

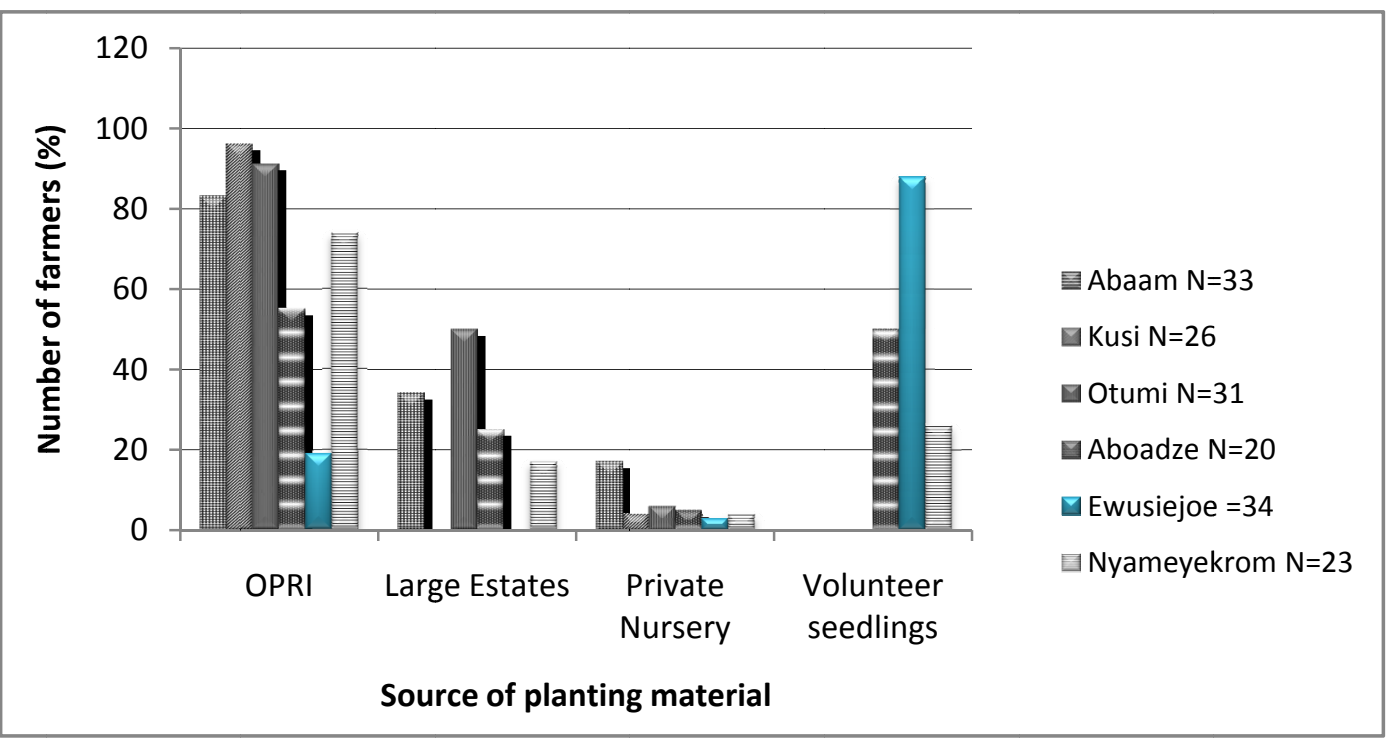

Figure 2. Source of planting materials for small-scale farmers in six oil palm growing communities in Ghana (It must be noted that the sum of several bars in a community may be more than $100 \%$ because farmers may source planting materials from more than one source) 


\subsubsection{Oil Palm Management}

Most small-scale farmers plant more than the recommended number of plants per hectare (which is 150 seedlings) (Table 1) with the hope that at the end of the life cycle of the palm they could get more money from the sale of the trees for the production of alcohol. There were also significant differences between the communities. In Otumi most farmers applied the recommended number. Otumi is within the catchment area of the GOPDC where the out-grower system by the company has had tremendous impact on the farmers. Although farmers who plant at high density are bound to get higher income from the sale of trees at the terminal life of the plantation, the income obtained from sale of trees will not be able to compensate for loss of income from sale of fruits due to closer planting. Poor uptake of technical innovation by farmers in the oil palm sector is responsible for low fresh fruit bunch (FFB) yield especially among farmers in the Ahanta West District which is 4.5 tons per hectare compared to 9.3 tons/ha in the Kwaebibrim District (Table 2). The difference in yield between the two districts is mainly due to differences in the use of planting materials (Figure 2) although other factors such as spacing, field maintenance and soil factors could not be ruled out.

\subsubsection{External Inputs}

The use of fertilizers is very low among smallholder farmers (Table 1). Most farmers did not apply fertilizers. Only half of the farmers at Otumi occasionally applied fertilizers. As a consequence of lack of fertilizer use a system innovation has emerged where some farmers in the Kwaebibrim District completely switched from conventional oil palm production to organic oil palm production which is a newly emerging production system for the production of organic palm oil for markets in Europe and United States. Although it is the oil palm field that is certified as organic, the product that enters the organic market is the palm oil. The cost of certification is borne by the buyer of the fruits.

Table 2. Fresh fruit bunch yield of oil palm in two oil palm growing districts in Ghana

\begin{tabular}{ll}
\hline District & Fresh fruit bunch yield $\left(\right.$ ton $\left.\mathrm{ha}^{-1}\right)$ \\
\hline Ahanta West & 4.50 \\
Kwaebibrim & 9.30 \\
& \\
SED & 1.47 \\
$\operatorname{Pr}>$ F & 0.05 \\
\hline
\end{tabular}

However, if the farmers are well organized, they can pay for and own the organic certificate themselves. If the project is a social and fair-trade project, the farming communities also get social and fair-trade premium which is about $10 \%$ of total cost of production of the quantity of oil that is produced and exported. This money is used to undertake development projects in the communities besides the organic premium received by the individual farmers which is also $10 \%$ of the prevailing market price. About 250 small-scale private farmers have had their farms covering about 800 ha certified as organic and social and fair trade. The Ghana Oil Palm Development Company also has most of its out-growers certified as organic. The farmers are however not getting the organic premium because the company is currently not selling its $\mathrm{CPO}$ as organic because the market of the conventional market is quite good and will only sell as organic when the market becomes poor. Herbicide use is also scarce, with the majority of farmers never using herbicides, but there were no differences between the communities (Table 1). As a consequence of lack of herbicide use, farmers had to weed more than once per year (Table 1).

\subsubsection{Land Tenure}

One institution that has negative impact on investment in improvement in the farm by smallholder farmers is land tenure. Several types of land tenure arrangements exist in the oil palm system. These include own land, share cropping ("Abunu" and "Abusa") and lease arrangements (Figure 3). Under the "Abunu" system of share cropping, the landowner (most of whom do not have enough resources to invest in the land) provides land while the tenant farmer provides inputs and labor. In such a situation, the field may be shared between the tenant and the landowner after five years on 1:1 basis or the tenant may maintain the farm and use a third of the income from the sale of the fruits for field maintenance, keep a third of the money for himself and give a third to the landowner. In the "Abusa" system of sharecropping which is prevalent with out-grower schemes of the large industrial estates, a tripartite contract is signed among the management of the estate, the tenant farmer and the 
landowner. The landowner provides land, the estate provides inputs (fertilizer, planting material, money for maintenance and extension service) while the tenant farmer provides labor. When the trees come into full bearing, the fruits are sold to the company which then deducts part of its input cost at source. The estate usually starts deducting its input cost 7 years after planting and deduction continues for about 20 years. After the estate has deducted its input cost, the rest of the money is shared between the tenant farmer and the landowner at the ratio of 2:1. Field maintenance cost such as weeding and pruning as well as harvesting and bulking cost are borne by the tenant farmer from his share of income from the produce. During the peak season (Feb.-May), price of fruits goes down and after deduction of input cost by the estate, very little income is left to be shared between the tenant and the landowner. What the tenant normally gets is only able to pay for harvesting and bulking cost. During peak fruit production season, tenant farmers divert the fruits and sell to small-scale processors so that they can avoid deduction by the estate. When out-grower farmers fail to send their fruits to the company to avoid deduction, the company may send the farmer to the law court for which the farmer may be prosecuted. The current system of share cropping within the large industrial estates, whereby the tenant farmer uses part of his income from the sale of fruits for paying harvesting and bulking cost in addition to regular maintenance costs, reduces the tenant to a mere laborer for his landlord. The lease arrangement is common only in the Western Region (Figure 3). Under this arrangement the land is leased to the prospective tenant farmer by the landowning family and it is validated by the Chief. This involves payment of some token amount of money to the landlord annually in addition to the onetime payment that is paid in bulk. The contract is also written in most of the cases.

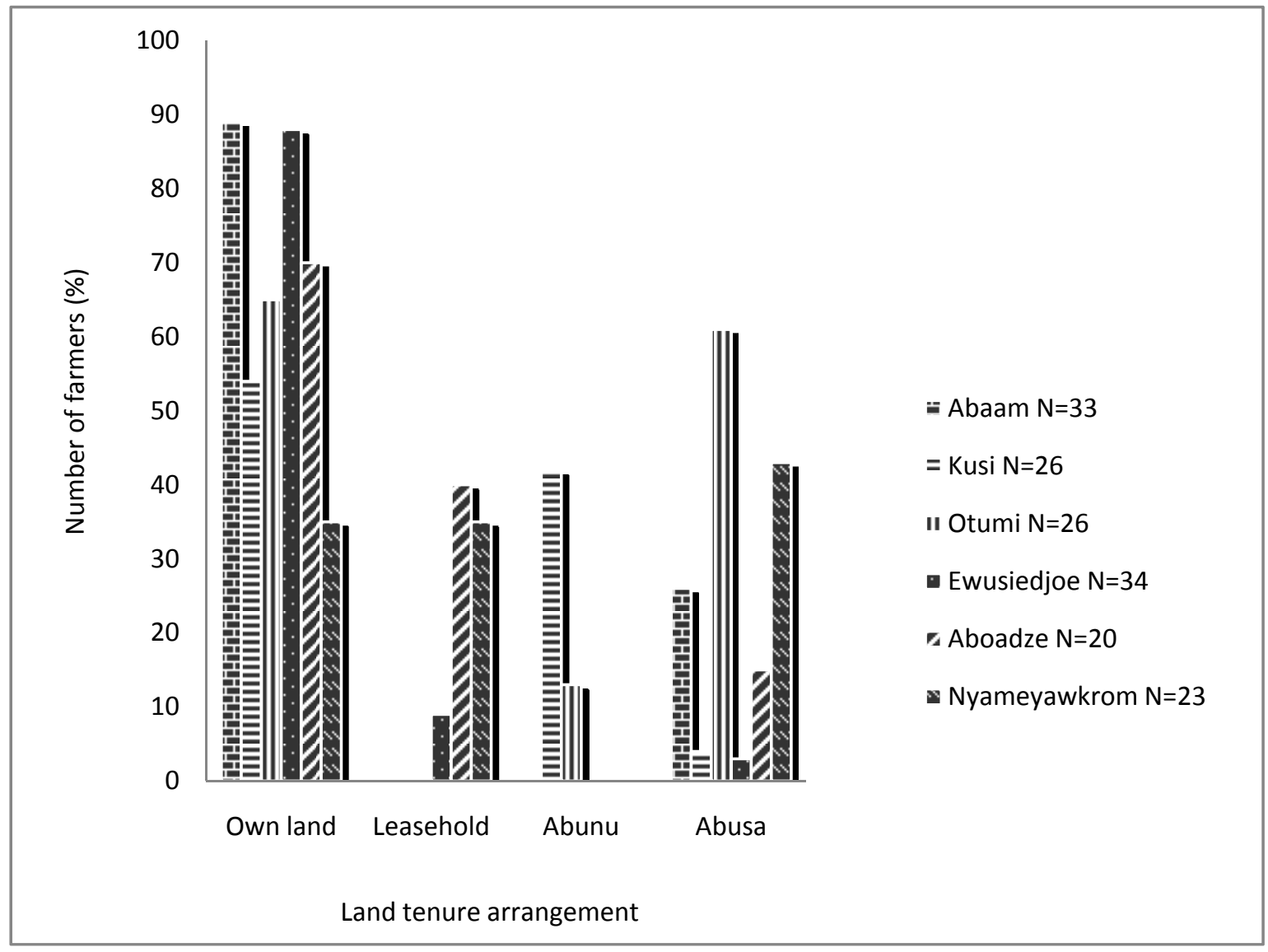

Figure 3. Land tenure arrangements in six oil palm growing communities in Ghana (In some villages the total number of farmers may add up to more than $100 \%$ because some farmers may access land for cultivating oil palm from more than one source)

\subsubsection{Emerging Institutional Innovations}

Some forms of institutional innovations have emerged in the sector. These include: (1) the use of weighing scale for weighing fresh fruit bunches at the farm gate to reduce cheating of farmers by small-scale processors, (2) the use of buying agents for purchase of fruits to ensure prompt payments of farmers for their produce and (3) the 
introduction of lease system (50 years) as an arrangement for securing access to land for oil palm cultivation. The lease arrangement is peculiar to the Ahanta West District (Figure 4). These institutional innovations have also taken place mainly in the Ahanta West District. This may be related to the long history of oil palm cultivation in this district which dates back to the colonial period. For instance the use of weighing scale for weighing fruits at the farm gate traces its history to the colonial era when the Lever Brothers were using weighing scale to purchase fruits harvested from the wild by farmers.

The emergence of small private oil palm farms following the devastating effect of the bush fires on the cocoa industry beginning from the year 1983 led to the proliferation of small-scale processing mills in the major oil palm growing areas. In the Kwaebibrim District, between 42 and $80 \%$ of the farmers sell their produce to the women who process palm fruits at the local milling sites commonly known as "Kramer" (named after a Belgian engineer who first set up a small-scale mill in the district in 1982 (Osei-Amponsah et al., 2012)) (Figure 4). However, the practices of these processors which involves storage of fruits for a period ranging between 1 and 3 weeks before processing results in the production of poor-quality oil (i.e. high free fatty acids, high moisture content and high impurities). Furthermore, the absence of policies regulating the activities of small-scale processors often results in environmentally unfriendly and unhealthy practices that also impede their entry into the industrial and export markets. Besides, small-scale semi-mechanized mills are not efficient in oil extraction leading to low oil extraction rate (about 10-13.5\%) ( $\mathrm{Zu}$ et al., 2011) compared to those of large-scale mechanized mills whose extraction rates range between 19 and 22\% (J.E. Inkumsah, Former Managing Director, Ghana Oil Palm Development Company, personal communication). Inspite of these limitations, the small-scale processors get most of the fruits produced by small farmers because they pay farmers promptly and fruits are sold at the farm gate compared to the large and medium-scale processors who take between one and two weeks to pay farmers after fruit delivery at the mills. Most of the small-scale processors also pre-finance the operations of the small-scale farmers. Although this category of small-scale crude palm oil producers can produce about $80 \%$ of the total national CPO production (MASDAR, 2010), these oils cannot be utilized by the local refineries because of its poor quality in terms of free fatty acids, moisture content and impurities. This often results in glut during the peak fruit production period leading to low price of fruits produced by farmers. During the lean production season which spans from June to October and which also happens to be the peak of the rainy season, small-scale processors complain of high moisture and low oil content in the palm fruits which also lower their profit margin.

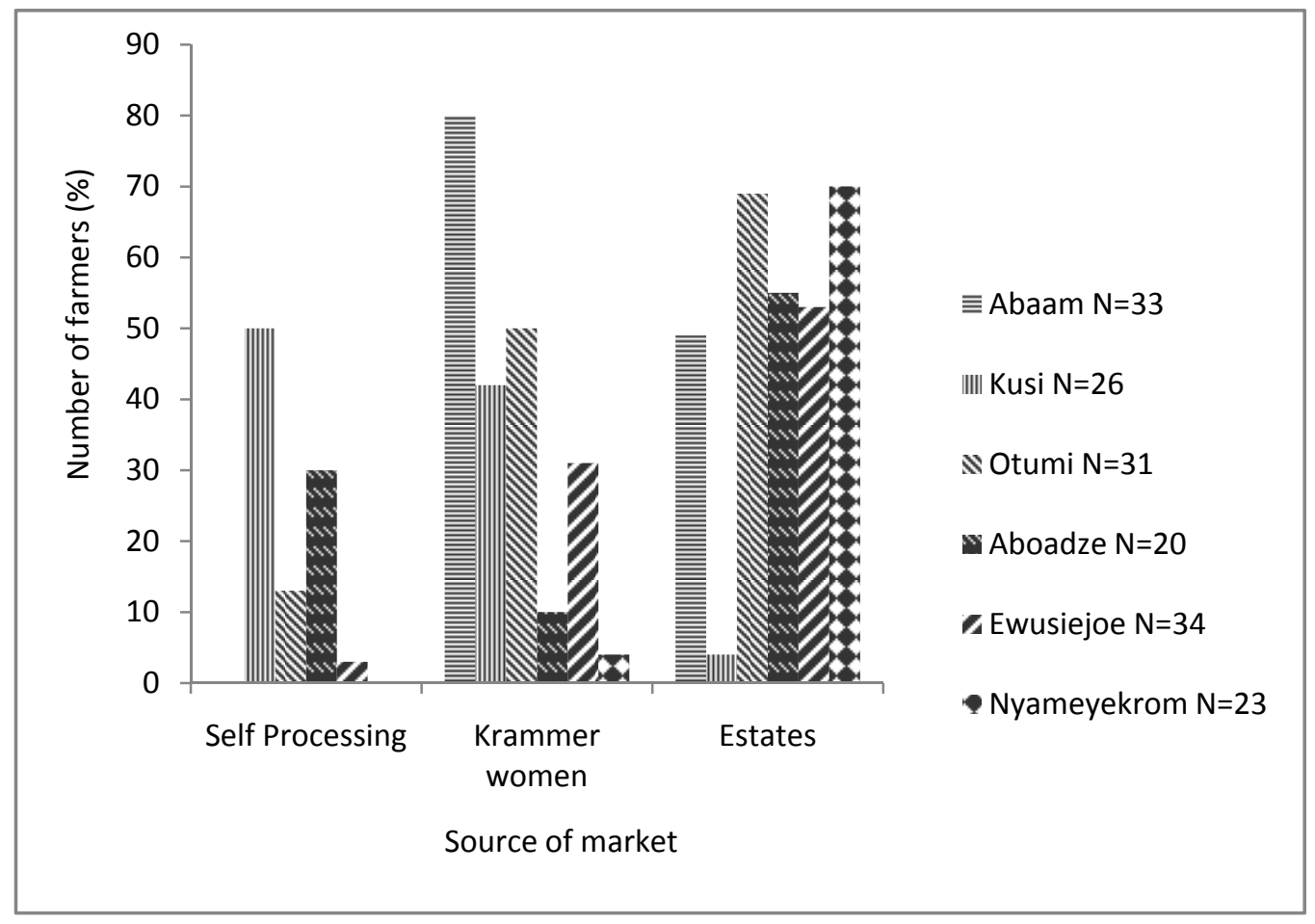

Figure 4. Source of market for fruits produced by for small-scale farmers in six oil palm growing communities in Ghana (The total number of farmers for some communities may add up to more than $100 \%$ because farmers may sell their fruits to more than one market) 


\section{Discussion}

The study highlights the diversity of actors within the sector and the respective roles played by them. The roles of the various actors have evolved over different periods in the history of the development of the crop.

\subsection{Technical Constraints}

The quality of palm oil produced by small-scale processors appears to be the most important constraint that needs attention. Palm oil extracted by semi-mechanized small-scale processors is said to be of low quality (in terms of free fatty acids, moisture content and impurity) as a result of poor processing practices being used by small-scale processors (Osei-Amponsah et al., 2012). Besides the quality of oil extracted, the oil extraction rate of these mills is very low. The quality differences between oils processed by the large industrial estates and the small-scale processors are mainly due to differences in processing practices. While small-scale processors store the fruits for periods ranging between one and three weeks before processing, with the erroneous belief that this practice could improve the oil yield, large-scale processors process their fruits within forty eight hours after harvesting. Storing the fruits beyond forty eight hours before processing, results in rapid deterioration of the fruits leading to the formation of free fatty acids. Several studies (Onwuka \& Akaerue, 2006; Owolarafe et al., 2008; Tan et al., 2009) have shown that storage of palm fruits before processing leads to high concentrations of build-up of free fatty acids mainly caused by action of lipase which breaks down fat molecules into fatty acids and glycerol before boiling of fruits (Olie et al., 1998) resulting in poor-quality palm oil. This prevents them from accessing the huge unsatisfied demand for high-quality oil in the remunerative market that exists both locally and externally. A study by Adjei-Nsiah et al. (2012) has shown that processors in Ghana make little or no profit during the peak fruit production season due to lack of remunerative market for the oil. Lack of knowledge about good processing practices and inaccessibility to extension services are partly to be blamed for the poor processing practices by small scale processors. Studies in Ghana (Adjei-Nsiah et al, 2012; Osei-Amponsah et al., 2012) and Nigeria (Akangbe et al., 2011) have shown that small-scale palm oil producers do not have access to extension services. The small-scale processors have however survived all these years in the wake of competition with large-scale processors and Asian producers partly due to lower overhead cost and also for the fact that the niche market for which they produce does not care so much about quality. Since small-scale processors in Kwaebibrim do not use weighing scale for purchase of fruits, they cheat farmers by underestimating the value of the fruits by as much as $20 \%$. For instance whereas an average of 65 fresh fruit bunches weigh one ton, the small-scale processors count as much as 80 fruits as one ton and when fruits are smaller than average, they count it twice.

\subsection{Institutional Constraints and Innovation}

Promoting oil palm development in Ghana thus requires institutional conditions that would encourage smallholder farmers and processors to use modern methods of production and processing to improve their income. These institutional conditions include: (1) access to land for oil palm cultivation under more favorable terms, (2) opportunity for farmers (especially farmers outside the catchment areas of the Oil Palm Research Institute) to get access to improved planting material for planting and (3) creating favorable condition that will allow small-scale processors to sell in the international market and the industrial market. Unfavorable land tenure arrangements especially within the areas of the large industrial estates serve as disincentives to sharecroppers to invest in the farm to increase productivity. One area which is also responsible for low productivity in the sector is the inaccessibility to improved tenera hybrid seedlings. Farmers in regions like the Western Region which is far away from the production center of the tenera hybrids mainly rely on volunteer seedlings which are mainly of the dura type for planting. In addition the current situation of the absence of effective farmers' and processors organizations in the sector is hindering farmers' access to markets under more favorable terms. Absence of regulatory body and processing regulations to regulate the activities of small-scale processors leads to a situation where processors use practices that do not conform to the international food safety standards recommended by Codex Alimentarius/FAO/WHO norms (2005).

In the Ahanta West District in the Western Region where farmers have difficulty accessing good-quality seedlings for planting, one way of improving the opportunities of farmers in this area is to create institutional conditions for improved system of distribution of improved planting materials. This could be done by organizing nursery operators in the area to produce certified planting materials. This requires training and support in terms of access to the improved hybrid seeds from the OPRI as well as certification and regulation.

Farmers in Kwaebibrim District have for many years sold their fruits to small-scale processors by just using visual appraisal for estimating the weight of fruits without using any weighing scale. Using weighing scales by small-scale processors to purchase farmers produce and having regular checks on these scales can avoid 
situations where farmers' produce are undervalued by small-scale processors.

Accessing international market and the huge industrial market that exist in the country and globally is an opportunity for small-scale farmers and processors especially in the Kwaebibrim District (which has the highest concentration of small-scale processors in the country) to gain remunerative price for their produce. But small producers and processors find it very difficult to access this opportunity because of poor quality of oil produced by small-scale processors and also because of their environmentally unfriendly and unhealthy processing activities. Accessing this opportunity requires support to help women processors change their practices. At the same time it requires work to create entry points to existing value chains through policy (e.g. bye-laws). A solution could be to experiment with small-scale processors and other actors along the value chain with different methods of processing that improve both oil extraction rate and the quality of palm oil produced in terms of Free Fatty Acid content, moisture content and impurities. Working towards creating entry into the existing value chains also requires bringing together inter-dependent actors who will be able to promote standards enforced by bye-laws and policies in support of the operations of smallholder processors.

Tenancy rules and agreements in the oil palm development is complex with different sets of people owning the land and having usufruct right to the trees. In the out-grower schemes where a tripartite agreement is signed among the landowner, the tenant farmer and the oil palm estates, tenant farmers are reluctant to invest in improvement in production and sell their fruits to the companies when price of fruits are low for fear that when credit deductions are made by the estates there will be little or no money left to pay for harvesting, bulking and maintenance costs which are all taken care by the tenant farmer after the income from sale of fruits has been shared. Thus developing appropriate tenancy rules and arrangements that will improve the profit margins of tenant farmers will encourage them to invest in farm productivity.

Small-scale oil palm farmers have little bargaining power. Although they feel that they are being cheated, they could do little about it because they have little or no economic power. Oil palm farmers in Ghana are not well organized. Where they exist, it has no representation at the community level. One opportunity for farmers to get adequate income for their produce is to organize themselves so that they can negotiate better deal for themselves.

\section{Conclusion}

The increased consumption of palm oil in recent years offers an array of opportunities for the development of the sector. These opportunities are however hampered by absence of institutional conditions that make it rational for smallholders to invest in increased production and processing as well as improved agricultural and environmental practices. Several opportunities in the oil palm industry have been identified that will develop the sector. These opportunities range from improving institutional conditions for small-scale processors for accessing international and industrial markets that exist in the country to facilitating organization of farmers so as to enable them to negotiate better deals. Achieving these objectives requires collaboration among the various actors in the sector, including the government, research and extension, smallholder farmers and processors, the large estates, public organizations with coordinating and regulatory functions and the small-scale millers.

\section{Acknowledgements}

The Authors acknowledge the financial contribution made by the Directorate General of International Cooperation of the Dutch Ministry of Foreign Affairs towards this work. We are grateful to three anonymous reviewers for their critical and constructive comments on an earlier version of this paper.

\section{References}

Adjei-Nsiah, S., Zu, A. K. S., \& Nimo, F. (2012). Technological and financial assessment of palm oil production in Kwaebibrem District, Ghana. Journal of Agricultural Science, 4(7), 111-120. http://dx.doi.org/10.5539/jas.v4n7p111

Akangbe, J. A., Adesiji, G. B., Fakayode, S. B., \& Aderibigbe, Y. O. (2011). Towards palm oil self-sufficiency in Nigeria: constaints and training needs nexus of palm oil extractors. Journal of Human Ecology, 33(2), 139-145.

Anon. (1999). Introduction to oil palm production. Better Crops International, 13(1), 3-6.

Asamoah, T. E. O. (1998). Farming and cropping systems: agro-management practices for sustainable oil palm production in Ghana. A paper submitted for the first biennial National Agricultural Systems (NARS) workshop, organised by NARP of Ghana, 16-20 ${ }^{\text {th }}$ November, 1998, International Conference Centre, Accra.

Amanor, K. S. (1994). The New Frontier: Farmers' Response to Land Degradation, A West African Study. Zed Books, London. 
Basiron, Y. (2007). Palm oil production through sustainable plantations. European Journal of Lipid Science and Technology, 109, 289-295. http://dx.doi.org/10.1002/ejlt.200600223

Codex / FAO / WHO. (2005). Food standards for oils and fats CODEX STAN 210, FAO / WHO.

Hounkonnou, D., Kossou, D., Kuyper, T. W., Leeuwis, C., Nederlof, S., Röling, N., ... van Huis, A. (2012). An innovation systems approach to institutional change: Smallholder development in west Africa. Agricultural Systems, 108(1), 74-83. http://dx.doi.org/10.1016/j.agsy.2012.01.007

IAASTD (International Assessment of Agricultural Science and Technology for Development). (2008). Summary for Decision Makers. http://www.agassessment.org

Inyan, A. (2002). Oil palm- a resource with an emerging revolutionary industrial potential. ACRM Magazine, 4, 6-9.

Jalani, B. S., Basiron, Y., Darus, A., Chan, K. W., \& Rajnaidu, N. (2002). Prospects of elevating national oil palm productivity; a Malaysian perspectivee. Oil Palm Industry Economic Journal, 2(2), 1-9.

MPOC (Malaysian Palm Oil Council). (2009). Ghana's edible oil sector awaits palm oil players. Malaysian Palm Oil Fortune, 4, 5-10.

Nederlof, E. S., Röling, N., \& van Huis, A. (2007). Pathway for agricultural science impact in West Africa. Lessons from the Convergence of Sciences Programme. International Journal of Agricultural Sustainability, $5(2-3), 247-264$.

Olie, J. J., \& Tjeng, T. D. (1998). The extraction of palm oil, Stork-Amsterdam, The Netherlands.

Opoku, J., \& Asante, F. A. (2008). Palm oil production in Ghana. Final report on the status of the oil palm industry in Ghana submitted to German Technical Co-operation (GTZ), Accra. pp. 100.

Onwuka, G. I., \& Akaerue, B. I. (2006). Evaluation of the quality of palm oil produced by different methods of processing. Research Journal of Biological Science, 1(4), 16-19.

Osei Amponsah, C., Visser, L., Adjei-Nsiah, S., Struik, P. C., Sakyi-Dawson, O., \& Stomph, T. J. (2012). Processing practices of small scale palm oil producers in the Kwaebibrem District, Ghana: A diagnostic study. NJAS-Wageningen Journal of Life Sciences (Special Issue) dx.doi.org/10.1016/j.njas.2012.06.006

Owolarafe O K, Taiwo E A and Oke O O. (2008). Effect of processing conditions on yield and quality of hydraulically expressed palm oil. International Agrophysics, 22(4), 349-352.

Presidential Initiative on Oil Palm. (2004). Modular business plan for developing 5000 hectares oil palm plantation. PSI-Oil Palm Secretariate, State House, Accra. pp. 157.

Presidential Initiative on Oil Palm. (2003). Policy document, State House, Accra.

Tan, C., Ghazali, H. M., Kuntom, A., Tan, C., \& Ariffin, A. A. (2009). Extraction and physiochemical properties of low free fatty acid crude palm oil. Food Chemistry, 113, 645-650. http://dx.doi.org/10.1016/j.foodchem.2008.07.052

Toledano, J., Kumar, S., \& Danielou, M. (2004). Tree crops development in Ghana. A reconnaissance mission report. GOG-World Bank-African Region-rural development tree crop development initiative.

van Huis, A, Jiggins, J., Kossou, D., Leeuwis, C., Röling, N., Sakyi-Dawson, O., Struik, P., \& Tossou, R. (Eds.) (2007). Research researched: can convergence of agricultural sciences support innovation by resource-poor farmers in Benin and Ghana? International Journal of Agricultural Sustainability, 5(2\&3), 89-264.

World Bank. (2006). Enhancing agricultural innovation: How to go beyond strengthening agricultural research systems. Washington DC. The World Bank.

World Bank. (2008). Agricultural innovation system: from diagnostics towards operational practices. Washington DC. The World Bank.

$\mathrm{Zu}$, K. S. A., Adjei-Nsiah, S., \& Bani, J. (2011). Effect of processing equipment and practices on palm oil yield and quality in Kwaebibrem, Ghana. Agricultural Research and Review, 1(1), 18-25. 